\title{
Globalisation and its influence on ethical decision-making in business: China and intellectual property
}

\author{
Arno Neveling, Daniel Malan \& Anna Yortt
}

\begin{abstract}
Ethical decision-making in business is influenced by various factors, including the external environment, organisational factors, and society. Business ethics in China have changed in the last few decades, predominantly as a result of globalisation. However, such changes can take some time to start to manifest, which is seen in the lag between policy changes and tangible changes in the approach to intellectual property rights, as observed in the patent application trends in China. A change in approach to intellectual property indicates to what degree various countries have embraced the opportunities presented by globalisation.
\end{abstract}

Keywords: Globalisation, business ethics, intellectual property, China

\author{
Arno Neveling* \\ Business Development Manager, Sasol, South Africa \\ Cradock Square, Rosebank, 2196 \\ arno.neveling@sasol.com \\ $+27(0) 836257145$

\section{Daniel Malan} \\ Senior Lecturer, \\ University of Stellenbosch Business School \\ PO Box 610, Bellville, 7535, South Africa \\ daniel.malan@usb.ac.za
}

\section{Anna Yortt}

Previously Research Manager: Centre for Corporate Governance in Africa, University of Stellenbosch Business School, South Africa

10725 Cyprus Court, Dawson Creek, British Columbia V1G4N1, Canada

annayortt@hotmail.com

* Author to whom correspondence should be addressed

\section{INTRODUCTION: DIFFERENCES IN ETHICAL DECISION-MAKING}

Ethical decision-making in business is influenced and shaped by various factors, including the external environment, organisational factors, and society. Business ethics in China and, consequently, ethical decision-making have emerged and developed mainly due to economic reforms in response to globalisation. Globalisation is hailed as a way to spread cosmopolitan values, as well as to enhance employment conditions and standards of living. However, it is also seen as a new wave of colonialism imposed by developed countries and multinational companies on poor

Arno Neveling is a Business Development Manager for Sasol, currently on assignment at a Sasol joint venture in Uzbekistan. Previously, he fulfilled roles in strategy formulation, development of governance processes, as well as research and development. Arno's qualifications include a doctorate degree in Chemistry, as well as a Master's degree in Business Administration (MBA), both from the University of Stellenbosch, South Africa.

Daniel Malan holds a Master's degree in Philosophy and an MBA from Stellenbosch University, and is a Senior Lecturer in Ethics and Governance and Director of the Centre for Corporate Governance in Africa at the University of Stellenbosch Business School, with a focus on corporate governance, business ethics, and corporate responsibility. He is a member of the World Economic Forum's Global Agenda Council on Values, the International Corporate Governance Network's Integrated Business Reporting Committee, and the UN's Anti-Corruption Working Group on PRME.

Anna Yortt is currently on a career break. Previously, she was the Research Manager at the Centre for Corporate Governance in Africa. During this time, she was responsible for managing research for the JSE SRI Index, as well as the Public Investment Corporation Corporate Governance Rating Matrix. Anna has a Master's in Business Administration from the University of Stellenbosch Business School. 
countries, synonymous with exploitation and impoverishment of both people and nature (Brennan, 2006:133).

Küng (1997:18) argued that economic globalisation requires globalisation in ethics, with minimum specific ethical values with basic attitudes and standards that are binding on all nations and all classes.

In traditional Chinese culture, ethics plays a central role in Chinese society, but business ethics in China is a new discipline. The practice of business ethics is still weak, and transforming theory into practice is key (Hong, 2001:90).

Business ethics, and thus ethical decisionmaking, in China has emerged and developed mainly in response to economic reforms (Xiaohe, 1997:1509), while the development process of business ethics was driven mainly by four factors: reflections on economic reform, the legacy of Chinese traditional ethics, the influence of Marxist philosophy and ethics, and the influence of business ethics from abroad. The four factors can be rephrased as the economic system, culture, the political system, and the influence of globalisation.

As globalisation resulted in a knowledge economy, China encountered many new ethical issues (Lu, 2001:113), such as the justification and protection of intellectual property (IP), and the role of government in the protection of IP and public interests (Lu, 2001:117). IP can be defined as intangible assets that include brand value, patents, know-how, copyright, trademarks, and designs (TaylorWessing, 2008:4). According to the European definition, an invention must be new, non-obvious, and industrially useful to be patentable (Davis, 2004:401). Trademarks are signs or symbols to identify goods and services, whereas copyright protects original literary and artistic works.

IP has become a global issue because of the interconnectedness brought about by globalisation. For companies operating in the global market, the safeguarding of IP in developing economies is just as important as in developed countries. The Internet provides a further challenge to intellectual property rights (IPR), from counterfeit goods being sold, to domain name- and trademark piracy. IP protection and patents, the IP type that is the focus of this paper, play a critical role in motivating innovation and competition amongst countries in a globalising world where no country can survive economically in isolation (Botta and Tsai, 2004).

Historically, emerging markets were attractive to expanding companies for a number of reasons, such as affordable and skilled labour. However, companies must be careful in these markets, and develop a risk management strategy to effectively protect their interests. Whereas corruption is a big concern in Central and Eastern Europe, IP management is the concern when operating in China (Credit control, 2005). Interestingly, more companies are willing to take on the potential problem of corruption rather than the potential loss of IP, as shown by a survey of companies that contemplate expansion. A total of $74 \%$ of companies were investigating expansion into Central and Eastern Europe, as opposed to only $43 \%$ that considered China.

IPR were brought to the forefront of economic development in China in 1978, when China opened its door to the outside world. Economic development became the main focus of the country, and foreign direct investment (FDI) and technology transfer became the foundation of Sino-foreign relations (Yang, 2003:131). As a result, multinational companies could extend their reach and operations into China.

The most significant international development in IPR has been the signing of the agreement on Trade Related Aspects of Intellectual Property Rights (TRIPS) under the multilateral trade negotiations at the Uruguay Rounds. This was a major landmark in the discipline of International Law (Mathur, 2007:1). The extent of protection and enforcement of intellectual property rights varied widely around the world, and these differences became a source of tension in international economic relations. The TRIPS agreement is an attempt to narrow the gaps in the way intellectual property rights are protected around the world, and to bring them under common international rules. 


\section{THE INCREASING ROLE OF INTELLECTUAL PROPERTY RIGHTS IN THE AGE OF GLOBALISATION}

The increasing role of IPR can be explained by four interrelated trends. Firstly, intangible assets are increasingly a source of competitive advantage. Secondly, business activities are becoming more globalised. Thirdly, advances in digital technologies make replicating and transferring easier, and, finally, there are significant changes in many countries in the legal framework that governs the strength and scope of IPR (Davis, 2004:400).

However, some do not look favourably upon IP protection. Griffin (2003:794) postulated that the move towards protection is in the wrong direction. Lawyers go through enormous effort to establish ownership of ideas (patents and trademarks) that can give companies or individuals extremely valuable monopoly privileges. On the positive side, together with the highly competitive global work environment, the major challenge for companies is to innovate faster (Erez and Gati, 2004:591).

Despite negative feelings towards IP protection, developing countries are dependent on companies in the developed world for technology (Bosworth and Young, 2000:454). Many countries have policies in place to obtain technology from abroad. International firms, through inbound foreign direct investment (FDI) and licensing activities, represent a ready conduit to obtain technology.

IP regulations have been tied to trade-access negotiations ever since the birth of the WTO, in 1994, which was formed as a result of the increase in trade, a direct result of globalisation. As a result, and as a by-product of globalisation, the rules of the game that affect the use of technology, and thus IP, changed (Teitel, 2005:458).

However, despite WTO efforts and the TRIPS agreement, there is still flexibility in adjusting national systems to national requirements, taking into account the trade-off between public good and private interest, even though there is a tendency towards convergence in national and regional systems, as a result of international treaties and agreements (WIPO, 2007:vi).

Linking IP regulations to trade agreements was initially pursued by industrialised countries, such as the USA, in an effort to stop the sale of counterfeit copies of copyrighted and trademarked goods. Bird (2006) mentioned action by the United States government that led the BRIC countries (Brazil, Russia, India, and China) to change their legal landscapes. Although all four of these countries now have stronger IP laws, enforcement thereof remains a different matter altogether.

China has a reputation as a 'pirate nation' with a complete disregard for IP (Grulke, 2006:40). One recent example was the Shanghai automobile show of 2003 (Grimes, 2005), where GM launched a new $\$ 9000$ compact car, only to find a similar Chinese version on the floor for \$6 000. GM lost the subsequent court case, as the courts ruled: "GM has no evidence for the case." Another example was when Toyota found another manufacturer using the Toyota logo on their cars. Toyota also lost, as the court ruled that China did not recognise the Toyota brand.

Legal and administrative differences in national or regional patent systems have a significant impact on the number of patents being filed (WIPO, 2007:vi), as do a number of other factors. The size of the country also plays a significant role. To some extent, the differences between patent offices reflect the stage of industrial development, international trade, and investment in the respective countries.

A country's approach to international trade involving technology management, ownership of knowledge, and business processes is strongly influenced by interknitted societal, moral, and ethical issues (Ganguli, 2000:168). Copying, an ethical issue, is permitted in the absence of legally determined exclusive rights, and, in some societies, it is even encouraged.

According to Griffin (2003:795), the situation is far worse when it comes to technology patents, as opposed to trademarks. Griffin believes the 
answer lies in reforming the World Intellectual Property Organisation (WIPO), to make it more difficult for inventors to obtain patents. Four proposals are made, of which the first is to stop companies patenting minor product differentiations. Secondly, companies should be prevented from acquiring defensive patent portfolios consisting of a large number of patents as a way to choke competition and inhibit innovation by the competition. Another proposal is that companies should be prevented from engaging in anticompetitive strategies, such as litigation against smaller companies as a way to increase the costs of entry into the industry.

The social impact of IPR was demonstrated by a study by Adams (2008:729) that showed that strengthening IP rights, and openness of the economy, are positively correlated with income inequality around the world, while globalisation was found to explain only $15 \%$ of the variance in income inequality. There is another negative side to IPR. Collier (2000:72) mentioned the example where multinational companies attempted to patent genetic components of plants and animals, thus preventing companies in poor countries from using these to manufacture medicines, cosmetics, or foodstuffs. These patents were capturing ageold knowledge of indigenous people about uses and applications of these substances. Collier also mentioned that some companies have the technology to render seed infertile in order to enforce restriction of its use, even though farmers have been growing their own traditional crops, such as wheat and rice, in India.

Under the World Trade Organisation's (WTO's) TRIPS, India has ceded the right to free-ride on foreign advances, something India's generic drug makers used to exploit very well (The Economist, 2007:8). India now grants 20 years of patent protection to inventions made since 1995. It hopes that the tighter laws will inspire new exploits in innovation and, in addition, reassure foreigners who are still wary of inventing or making original products in India. A recent study by the World Bank expressed the hope that the strategy will succeed (Dutz, 2007:38).
During the period from 1950 to 1980, countries in Latin America and East Asia, then in the earlier stages of industrialising, incorporated and adapted technology relatively freely (Teitel, 2005:458). The TRIPS agreement emphasises faithful adherence to patent laws and other IP restrictions, making this much less likely today. Until recently, some countries, including India, had IP regulations that permitted the patenting of certain new products, but not their manufacturing processes. This is not permitted by TRIPS. In the medical field, this may lead to higher health costs, due to price differences between patented and generic products, and also serve as a disincentive to local innovation in this field, because local innovators used to search for alternative ways to manufacture patented chemical or pharmaceutical products.

Even though China has joined the WTO, and is thus bound by TRIPS, it is still argued that China will continue violating these provisions. However, in an unprecedented move in February 2008, China lost before the WTO over its import restrictions on car parts. The Economist (2008:69) argued that, on a symbolic and practical level, the case may be a turning point for many industries in China, and the start of a new era in which China is attacked by litigation.

\section{THE CHANGING FACE OF IP AND ITS PROTECTION}

Boldrin argued that both economic and social progress are the result of the persistent creation of new ideas and goods, their free exchange, and competition among creators, producers, and imitators of goods and ideas. Boldrin (2006:25) further argued that IP laws protect a monopoly on how other people make use of ideas.

Currently, the protection of IP is a sensitive issue that receives a lot of attention in the WTO. However, the fear of losing IP rights is an old phenomenon. During the eighteenth and nineteenth centuries, inventors had to simultaneously submit patent applications in all the countries where the inventor wanted patent 
protection, or risk ending up with no patent protection for all except one of the nations to which the patent was submitted, with the reason being that the first application destroyed the novelty of any subsequent application (Bird, 2006:320). The lack of global protection was a burning issue, so much so that, in 1873 , inventors refused to attend an international exhibition of inventions in Vienna, for fear of losing their patent rights.

\section{From the Paris Convention to TRIPS}

The 1883, the Paris Convention for the Protection of Industrial Property established the principle of national treatment, which requires nations to grant foreign patent holders the same rights as given to its own citizens (Bird, 2006:321). The Convention required signatories to impose minimum standards of IP protection. Over time, the Convention has been revised extensively, and remains the foundation of international IP law. However, the Convention allowed for discretion on the part of countries, some of which excluded fields, such as pharmaceuticals, from protection. As a result, the Paris Convention failed to sufficiently limit piracy of IP.

Reshaping the global IP regime began in earnest between 1986 and 1994, during the early phases of the Uruguay Round of the General Agreement on Tariffs and Trade (GATT) (Bird, 2006:321). The process was driven by the United States, with support from Europe and Japan (Bird, 2006:322). However, developing countries, led by India and Brazil, initially resisted these efforts to link trade and IP rights under GATT, arguing that the discussion of IP rights exceeded GATT's original mandate (Bird, 2006:323). Developing countries considered WIPO, where they could effectively block any changes because they make up more than half of the membership, to be the appropriate forum.

By 1989, the developing countries had succumbed to US threats of trade sanctions, resulting in IP rights being placed on the GATT agenda. The eventual outcome was the adoption in 1994 of the Agreement on Trade-Related Aspects of Intellectual Property Rights (TRIPS) (Bird, 2006:324). This agreement provided broader protections for IP rights by establishing minimum terms of protection, and authorising trade sanctions against non-compliant nations.

A lot of coercion was necessary to convince countries such as India. During the 1989 Indian economic crisis, the United States pressured India through its influence over the International Monetary Fund (IMF), on which India depended to get through the crisis. India also depended on direct grants and trade from the US, also their biggest trading partner (Bird, 2006:329). Russia was pressurised by being placed on the Watch List in 1995 and the Priority Watch List in 1997, signifying its non-compliance with IP standards. Pressure on China to improve IP protection almost resulted in a series of trade wars between the US and China. During the 1990s, the US repeatedly threatened to impose sanctions against China, eventually resulting in China agreeing to improve and enforce its IP laws.

Up to the conclusion of the Uruguay Round in 1994, the scope and strength of IP protection varied between countries, for reasons such as varying levels of economic and technological development (Dutfield, 2005:533). TRIPS established enforceable universal minimum standards of IPR protection and enforcement. These relatively high minimum standards were an attempt to specifically resolve copyright piracy, unauthorised use of trademarks, and competition from firms producing generic drugs because they were not bound by law to respect patents. According to TRIPS, WTO member states are given the freedom to develop their own IPR laws, as long as they stay within the spirit of the agreement (Ganguli, 2000:168). Essentially, every country must find the balance that satisfies its own national interests while complying with the agreement, as depicted in Figure 1. 


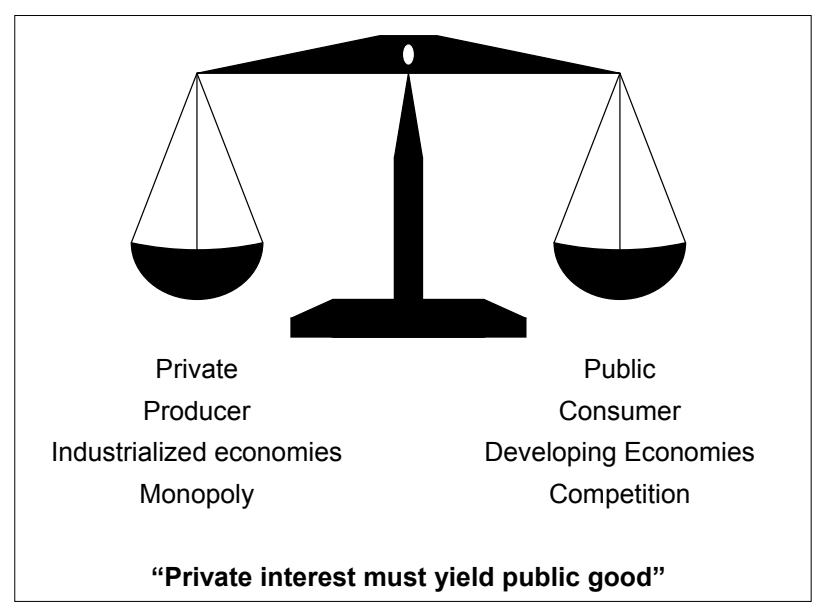

Figure 1: (Ganguli, 2000:168)

Anecdotal evidence suggests that illegal copying is important in the early stages of a country moving from a developing to a developed country, with Japan being a good example of this (Bosworth and Yang, 2000:454). The dilemma is that developed countries want their IP to be protected, and will go as far as applying sanctions to prevent developing countries from copying. With the eventual signing of TRIPS, the protection of IP became a key element of international trade negotiations.

TRIPS offers member countries some flexibility, with Asian countries being more proactive in making use of these flexibilities. India used these flexibilities of IPR rules to refuse patents on existing medicines, specifically the provision in Patent Law that states that patent monopolies will only be awarded for "truly innovative medicines" rather than minor changes to existing ones (Adams, 2008:732). The flexibility provides developing countries with the opportunity to pursue economic and social goals, including measures necessary to protect public health and nutrition (Mathur, 2007:5). However, developing countries must find a balance between protecting their national interests and the interests of the international community (Shen, 2005:197).

IPR protection is recognised as part of the legal infrastructure that supports investments in research and development, which, in turn, leads to innovation and, subsequently, to economic development. However, it is difficult to envisage this happening in the 50 least developed countries
(LDCs) that filed just ten global patents per year between 2000 and 2004 (Adams, 2008:732).

A recent review of empirical evidence found a statistically significant positive correlation between stronger IPR protection and higher levels of technology transfer under TRIPS, although a number of limitations were identified (Watson, 2011). Another advantage of IPR is that it stimulates local innovation and the transfer of technologies that foster local innovation. Since 1995, when the TRIPS agreement came into force, developing and the least developed countries have undertaken significant reforms in their IP systems. In addition, the developing and least developed countries experienced large growth in foreign direct investment, import of both goods and service, patent applications by foreigners and locals, and increases in researchand-development-to-gross-domestic-product (GDP) ratios.

La Croix and Konan (2002:760) argued that China's desire to become a member of the WTO fundamentally changed the nature of their approach to IP. The IP systems of India and China were flawed and practically powerless to provide real protection to inventors prior to the 1970s (Botta and Tsai, 2004:1). Botta and Tsai argued that reforms of their IP position in order to be competitive in the new global economy are a direct result of globalisation. This desire to join the WTO overcame the limited capacity of China's legal system and society's willingness to rapidly change in response to both domestic and foreign pressure. China had to make these changes to appease the US and the EU, and thus prevent a veto to ascension to the WTO.

The playing field for filing patents has changed in the age of globalisation. Multinational companies nowadays often introduce products into a number of markets at the same time, a practice that requires comprehensive international IPR protection right from the start (Davis, 2004:402). Previously, the practice was to introduce products locally, and then gradually expand to international markets.

The ease with which IP can be protected, 
defended, and exploited differs from jurisdiction to jurisdiction. IP decisions are increasingly impacted by a range of IP regimes, a consequence of the increasingly global economy, the growth of the internet and knowledge-based economies, and low-cost travel.

\section{The importance of IP}

Analysis performed by Mondal and Gupta (2006:29) indicated that strong IPR around the globe can improve the welfare of both developed and developing countries.

The conventional wisdom, as advocated by the Washington Consensus, is that continued economic growth will result in the expansion of the middle class, increased employment, and a higher savings rate among the poor, consequently resulting in the reduction in income inequality (Adams, 2008:726). This implies that, in order for developing economies to catch up with the living standards of developed countries, they must open their markets by lowering tariffs, removing trade restrictions, granting privileges to foreign investors, and enforcing IPR. Some studies suggested that strengthening IPR in poor countries can stimulate invention and new technologies. A recent WIPO report noted that intangible assets, such as knowledge, are replacing traditional tangible assets as the driving forces of economic development. Evidence, however, indicates the opposite. Latin American and African countries have more open economies and stronger IPR protection than Asian countries, but the level of income inequality is lower in Asia. Chu and Peng (2011) also found that better patent protection increases both economic growth and income inequality.

In compiling the first Global Intellectual Property Index (GIPI), TaylorWessing (2008:4) cited a study that suggested that only $20 \%$ of the average company's value is made up of tangible and financial assets. The remaining $80 \%$, excluded from book value, can broadly be viewed as IP, including brand value, goodwill, patents, knowhow, copyright, and trademarks.

\section{Lack of trust in IPR in developing countries}

Today, despite TRIPS, the lack of IPR protection in many countries is regarded by many as the single most significant threat to international competitiveness (Bird, 2006:319). Companies in developed countries are rarely willing to license technology to companies in developing countries that do not have comprehensive IPR laws together with their effective enforcement (Bosworth and Yang, 2000:453). The successful enactment and enforcement of such laws in developing countries should result in greater cross-border flows of IP from companies in developed countries to the developing world. Bosworth and Yang (2000:454) argued that the protection of IP is now at the forefront of the globalisation of markets in ideas, technology, and economics.

However, companies cannot afford to ignore the market opportunities in the large emerging market countries, especially the BRICS. This leaves many companies in developed countries in a predicament. The BRIC countries (excluding South Africa) do not yet have fully developed IP protection and enforcement mechanisms.

\section{A changing approach to IP}

A number of different treaties, of which the TRIPS agreement is the most significant, resulted in the standardisation of international IPR laws and enforcement mechanisms, extending these rights to most countries in the world. For some types of technology, trade secrets are adequate protection, but, in most cases, patents are necessary. IP laws need to be strong, effective, and enforced, if licensing from abroad is to be encouraged (Bosworth and Yang, 2000:454).

The internationalisation of IP from the late $20^{\text {th }}$ century onwards was accelerated by the globalisation of cross-border businesses (Yang and Clarke, 2005:549).

Furthermore, the scope of IP expanded dramatically. Some new areas that need a standard approach across the world and that currently are under discussion are the Internet domain, access to drugs, and e-commerce. Computer programs and databases currently need to be 
protected across different IPR, namely patents, trade secrets, and copyrights, depending on the country concerned.

Growing competition from developing countries in Asia and Latin America means that multinational companies have had to change their approach to patenting. The globalisation of business activities has also profoundly affected company patenting policies (Davis, 2004:405). Multinational companies used to apply for patents in selected countries that were earmarked as markets for their goods, but nowadays seek much broader international protection for their goods.

Patent philosophies also changed over time (Davis, 2004:408). In the past, innovators only patented selectively, patenting products and not the method, which was kept as a trade secret. Today, this poses a risk to companies, because other companies can patent the process and thus block the original inventor.

\section{The Global Intellectual Property Index (GIPI)}

The virtues and limitations of the various IP regimes differ significantly. TaylorWessing (2008:4) developed the GIPI to provide a point of reference by which the IP regimes of different jurisdictions can be assessed. The overall inaugural GIPI results of 2008 and the fourth (TaylorWessing, 2013) and latest (2013) ratings (with 36 jurisdictions and also including designs and data-protection indices) are set out below, showing the rank and rating for each jurisdiction. The list of jurisdictions in the indexes is divided into tiers to allow for statistically marginal differences (TaylorWessing, 2008:6).

In the inaugural index, the original four BRIC countries (Brazil, Russia, India, and China) formed the lowest tier for each of the separate indices and the combined GIPI by a significant margin. China was at the bottom of each index, more than 300 points lower than any of the Tier 1 jurisdictions. The latest index indicates that the gap is closing, now standing at less than 100 points. The original four BRIC countries have seen some of the highest increases in ratings since GIPI1, but they still languish at the bottom of the rankings. South Africa, the newest member of BRICS, has the most established IPR regime of the group. It appears to have dropped significantly since the first ranking, but when ignoring newcomers to the ranking, it dropped only marginally. However, it is ranked amongst the lowest of all the jurisdictions for attacking patent registrations, while the backlog of cases at the registry is a concern, together with it not permitting multi-class applications (TaylorWessing, 2013:25).

TABle 1: Original GIPI ratings (2008)

\begin{tabular}{|c|c|c|c|c|c|c|}
\hline Jurisdiction & $\stackrel{\square}{\square}$ & 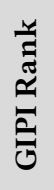 & 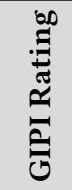 & 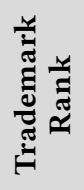 & 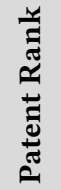 & 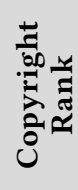 \\
\hline UK & & 1 & 768 & 1 & 1 & 2 \\
\hline USA & 1 & 2 & 762 & 6 & 2 & 1 \\
\hline Germany & & 3 & 749 & 2 & 3 & 3 \\
\hline Netherlands & & 4 & 740 & 3 & 4 & 4 \\
\hline Australia & & 5 & 733 & 4 & 6 & 7 \\
\hline Canada & & 6 & 732 & 7 & 5 & 5 \\
\hline New Zealand & & 7 & 724 & 5 & 7 & 6 \\
\hline Singapore & & 8 & 709 & 8 & 8 & 8 \\
\hline France & & 9 & 693 & 9 & 9 & 9 \\
\hline Israel & & 10 & 664 & 10 & 11 & 10 \\
\hline Japan & & 11 & 659 & 12 & 10 & 11 \\
\hline Spain & 3 & 12 & 652 & 11 & 12 & 12 \\
\hline South Africa & & 13 & 619 & 13 & 14 & 14 \\
\hline South Korea & & 14 & 619 & 14 & 13 & 13 \\
\hline Poland & & 15 & 576 & 15 & 16 & 16 \\
\hline Dubai (UAE) & 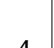 & 16 & 575 & 16 & 15 & 18 \\
\hline Italy & & 17 & 571 & 17 & 17 & 15 \\
\hline Mexico & & 18 & 550 & 18 & 18 & 17 \\
\hline India & & 19 & 489 & 20 & 19 & 19 \\
\hline Brazil & 5 & 20 & 484 & 19 & 21 & 20 \\
\hline Russia & 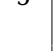 & 21 & 480 & 21 & 20 & 21 \\
\hline China & & 22 & 448 & 22 & 22 & 22 \\
\hline
\end{tabular}

In GIPI1, China, Brazil, Russia, and India were all regarded as very poor jurisdictions in which to manage all forms of IP. However, China recently joined the two key WIPO treaties for copyright protection (TaylorWessing, 2008:8), while Russia has made strong commitments to improve with 
the launch of a new IP court (TaylorWessing, 2013:32). Russia's move into the fourth tier is most probably the result of the overhaul of its IP laws, for the third time in a decade.

As far as trademarks are concerned, China's IP regime is reforming rapidly. This was attributed to China being the host of the 2008 Olympics and two WTO complaints filed by the US government (TaylorWessing, 2008:12). Not only has legislation been amended, but there is also greater buy-in from senior officials and professionals. Additionally, enforcement against counterfeiters, demonstrated by recent successes for Pfizer and Louis Vuitton, has been more effective. In 2006, there was a five percent increase to more than 14000 civil IP trials related to trademarks. However, counterfeiting remains a significant problem, with a reported $70 \%$ of all global counterfeit goods originating from China (TaylorWessing, 2013:31). In recent years, China has been developing an increasingly sophisticated patent system. The Supreme People's Court and the State Intellectual Property Office (SIPO) have been actively making and proposing changes in multiple areas, including infringement, claim amendment, enforcement, and compulsory licensing (TaylorWessing, 2013:32). China is also making changes to its copyright laws. However, it is still perceived that, in China, copyright is often unenforceable, and the benefits of copyright are not understood (TaylorWessing, 2008:17).

The slow processing of trials in India creates a negative perception of their IP regime (TaylorWessing, 2008:17), with the enforcement of patents, in particular cost effectiveness, adding to its low ranking (TaylorWessing, 2013:33).

Improvement in Brazil includes the modernisation of the Brazilian National Institute of Intellectual Property, with the aim of reducing the grant time of patents (TaylorWessing, 2013:31). Trademark filings have increased almost $200 \%$ in Brazil since GIPI3 in 2011, and enforcement by the National Council to Combat Piracy has also been improved. However, delays in both the registry and the courts mean that the trademark system remains a key weakness. It is believed that the hosting the football World Cup in 2014 and the Olympics in 2016 will result in the greater recognition of the value of IP within Brazil (TaylorWessing, 2013:20).

TABLe 2: GIPI RATings for SElEcted COUNTRIES IN 2013 AND 2008

\begin{tabular}{|c|c|c|c|c|c|c|c|}
\hline Jurisdiction & $\stackrel{\Xi}{\leftrightarrows}$ & 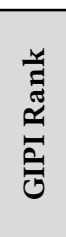 & 苞 & 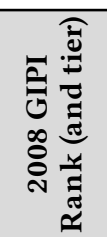 & 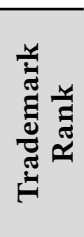 & 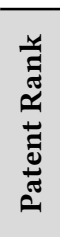 & 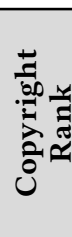 \\
\hline UK & & 1 & 657 & $1(1)$ & 1 & 2 & 1 \\
\hline Germany & & 2 & 656 & $3(1)$ & 2 & 1 & 4 \\
\hline Netherlands & 1 & 3 & 655 & $4(2 \uparrow)$ & 5 & 3 & 12 \\
\hline Sweden & & 4 & 653 & - & 6 & 4 & 4 \\
\hline Australia & & 5 & 652 & $5(2 \uparrow)$ & 3 & 7 & 17 \\
\hline New Zealand & & 6 & 643 & $7(2)$ & 4 & 9 & 13 \\
\hline Switzerland & & 7 & 643 & - & 10 & 5 & 7 \\
\hline France & , & 8 & 642 & $9(2)$ & 9 & 7 & 6 \\
\hline USA & 2 & 10 & 639 & $2(1 \downarrow)$ & 10 & 11 & 2 \\
\hline Canada & & 11 & 638 & $6(2)$ & 7 & 13 & 13 \\
\hline Singapore & & 12 & 637 & $8(2)$ & 13 & 9 & 3 \\
\hline Japan & & 15 & 628 & $11(3)$ & 15 & 12 & 9 \\
\hline South Korea & 3 & 18 & 620 & $14(3)$ & 20 & 15 & 9 \\
\hline Israel & & 20 & 615 & $10(3)$ & 19 & 19 & 22 \\
\hline UAE & & 24 & 598 & $16(4 \uparrow)$ & 25 & 24 & 23 \\
\hline Saudi Arabia & & $=25$ & 591 & - & 26 & 27 & 30 \\
\hline South Africa & & $=25$ & 591 & $13(3 \downarrow)$ & 24 & 29 & 33 \\
\hline Turkey & 4 & $=25$ & 591 & - & 29 & 28 & 26 \\
\hline Russia & & 29 & 588 & $21(5 \uparrow)$ & 32 & 25 & 25 \\
\hline Mexico & & 30 & 586 & $18(4)$ & 28 & 32 & 28 \\
\hline Brazil & & 31 & 581 & $20(5 \uparrow)$ & 31 & 33 & 27 \\
\hline Indonesia & & 34 & 572 & - & 34 & 34 & 36 \\
\hline China & 5 & 35 & 567 & $22(5)$ & 36 & 26 & 32 \\
\hline India & & 36 & 565 & $19(5)$ & 35 & 35 & 35 \\
\hline
\end{tabular}

\section{DEVELOPING BRICS COUNTRIES AND INTELLECTUAL PROPERTY}

Historically, the BRIC countries (prior to South Africa joining) were seen purely as countries with vast reservoirs of cheap labour (TaylorWessing, 2008:15). This is changing, as these countries are increasingly becoming knowledge-based economies, and have therefore started to adjust their systems to provide effective protection for the knowledge and developments that originate from within these countries. 
Developing countries regard technology transfer as possibly one of the most important areas of interest (Mathur, 2007:3). Empirical economic literature increasingly supports the view that technologies can be spread internationally through international trade and FDI (Park and Lippoldt, 2008:8). However, the pharmaceutical industry represents an industry where technology transfer to developing countries does not occur. Pharmaceutical companies rarely bother to register IP in developing countries, as they believe they stand no reasonable chance of earning a return (Wilson, 2007:24). On top of being expensive, registering a patent is further hampered by excessive regulatory burdens that require substantial paperwork and fees. The 2011 World Bank rankings on the ease of doing business and the regulations that enhance or constrain business activity illustrate this burden in developing countries (The World Bank, 2011). Of the original four BRIC countries, China performs the best, ranked only $79^{\text {th }}$ out of 183 countries. Russia is in position 123, India in position 134, and Brazil in position 127. This does not signify any improvement since 2008, when their ratings were $83^{\text {rd }}, 120^{\text {th }}, 122^{\text {nd }}$, and $125^{\text {th }}$ respectively out of 181 countries (The World Bank, 2008b:6).

Governments from countries with varying degrees of development see stronger IPR as an important part of their strategies to enhance FDI inflows and trade (Park and Lippoldt, 2008:8). In response to this view, some countries view trademark protection as a way to assure investors that they can combat imitations. Wealthier developing countries regard IPR as a means to draw in technology that can boost worker productivity, thus exploiting strong IPR policy, to draw in investment and encourage domestic innovation. India and China are two countries that reformed their stance towards IP in order to become more competitive in the age of globalisation (Botta and Tsai, 2004), a complete renaissance of their IP systems that, in the 1970 s, were flawed and powerless to provide real protection. The China, SIPO, originally established as the Patent Office of the PRC more than 30 years ago, now plays a central role in IPR, organising and co-ordinating
IPR protection work, improving the IPR protection system, establishing the collaboration mechanism of IP law enforcement, and implementing the China National IP Strategy, to name a few (SIPO, 2013A). SIPO recently released the Plan for Promoting the Strategy for the Development of National Patent Undertakings in 2013, with the aim of implementing key measures to reach the five-year goals of the National IP Strategy. These measures include the enhancing of IP creation, strengthening of IP layout in key industries, promoting the utilisation of IP, reinforcing IP protection, improving IP capacity, developing an IP service industry, and strengthening the development of an IP culture.

Developed and developing countries differ in opinion about the potential value of strong IPR. Botta and Tsai (2004) go as far as claiming that India's current status in the global economy may be attributed to its flawed patent policy. Japan emphasised incremental innovation through patent provisions, allowing industry to get closer to its international counterparts while allowing technology to diffuse through all sectors. Policies such as these have allowed countries like Korea and Japan to transform since the end of the Korean and Second World War respectively. However, since the Patent Amendment Acts of 1999 and 2002, and the liberalisation of economic policies, India was able to create a more Westernised notion of intellectual property rights in political and industrial parties. In short, India recently witnessed the rise of the modern, professional business that emphasises technology and economic advancement.

The argument that strong IPR can assist developing countries in alleviating poverty can be found in an agricultural example. The vast majority of poor people in the rural areas of developing countries are dependent on agriculture to survive (Lalitha, 2004:187). Consequently, new technology that can result in improved yield or reduced production cost will also directly reduce poverty and indirectly help the poor by lowering the price of food. However, India's new patent regime can have immense consequences for agriculture, which provides two-thirds of all Indians with 
their livelihood (Mathur, 2007:28). Commentators warn that ambiguous wording in the legislation could open the door for international companies to seek patents over commonly used seeds and slightly modified versions of these seeds that have been rendered resistant to cold, salt, and drought through thousands of years of agricultural practice. As much as 80 percent of all seeds used in planting in India are seeds saved from previous crops, and thus supplied by the farmers themselves.

Basant (2004:70) argued that the direction and quality of entrepreneurial innovation across all sectors of the economy are dependent on the legal framework of IP regimes within a country. The extent of IPR frameworks directly influences the ability of entrepreneurs to take advantage of commercial opportunities. Contracting and other transaction costs can be quite high in the absence of a suitable IP regime. Furthermore, the nature of the IPR regimes in a developing country can determine the ability of companies in that country to enter into partnerships with firms from industrial countries (Basant, 2004:75). Business and government in developed countries argue that IPR helps to stimulate economic growth and reduce poverty, whereas developing countries and non-governmental organisations (NGOs) argue that IPR can do little to stimulate invention in developing countries, because of a lack of the required human and technical capacity (Mathur, 2007:21).

Overall, the problem with IPR lies in implementation, with a general problem being that the enforcement mechanisms are either not functioning well, or there is a lack of willingness by authorities to act. Civil actions being pursued against some pirates are ineffective because disputes can take years to be adjudicated. Furthermore, light penalties fail to be a deterrent. When it comes to copyright piracy, Russia is far worse than Brazil. In terms of enforcement, IPR involves public interests and, consequently, it is likely that the governments will take social welfare into consideration (Liu, 2005:339). Bird (2006:332) mentioned that government action against illegal copying of academic books and other materials in Brazil is non-existent.

Enforcement of Russian IP laws is poor, while jail sentences as penalties are rare. India also suffers from a weak enforcement system (Bird, 2006:333). Other developing countries, like Argentina, also experience problems in effective enforcement of IP laws and provisions of the TRIPS agreement (Czub, 2001:193).

Despite threats of punitive measures by the US government, as well as the launch of enforcement initiatives, enforcement against local piracy and counterfeiting continues to be insufficient, (Bird, 2004:362). At present, China and Russia are viewed as the greatest threat to industries' copyrights. During 2008, there were a few positive developments, but piracy levels have not materially decreased (Security, 2008:33).

A factor that contributes to the lack of enforcement is that developing countries experience a lack of expertise in IP in academic institutions and in the legal profession (Shen, 2005:188). Another crucial problem is the lack of awareness and understanding of IP amongst key stakeholders and the general public.

Industries within developing countries are now playing a significant role in influencing IPR regimes. The strong IT sector in India is one such example (Basant, 2004:69). Large IT firms, together with firms in high-end niche areas, are dependent on strong IP regimes, as their growth strategies are IP-based. These companies typically seek IP protection in Western nations rather than in India itself, and nowadays even have a positive perception of restrictive IP regimes. IP-generation by subsidiaries of multinational companies in India is also contributing to this change in perception.

Most Indian firms that create IP tend to protect it in the US and other large markets, because it is essential to protect the invention within the relevant market. Most of the IP created in India is specifically for the Western markets (Basant, 2004:72).Furthermore, someIT-related inventions, such as algorithms and business methods, are not 
patentable in India, even though the IP regime in India has been made TRIPS compliant.

The Indian government has taken bold steps in modifications to their IP regime, steps that will have major implications for several sectors, including pharmaceutics, chemicals, biotechnology, and information technologyrelated sectors (Basant, 2004:70). The significant changes as a result of the IP changes will include the realignment of business strategies by firms in the abovementioned sectors. The role of IP is becoming more prominent as the underlying changes in the industry and technology environments create an increasing awareness of IP-related issues and a positive outlook on IPR (Basant, 2004:73).

However, enforcement of IP laws in India is still a problem, mainly because India's courts are very slow in administering justice. Courts sometimes take as long as ten years to pass judgement (Mehta, 2004:52). The establishment of an effective IPR regime is imperative if India is to be fully integrated into the international system and become a global patent centre. India became a signatory to TRIPS in 1995, after joining the WTO. Developing countries were given ten years as a transition period to bring their national laws in accordance with TRIPS, a time period that ended in 2005 (Mathur, 2007:27).

\section{CHINA AND IP}

Ning (2002:116) postulated that economically, culturally, and intellectually, China ought to make greater contributions to civilization and the construction of world culture, because China is a large country with a splendid cultural heritage.

\section{Cultural influence}

Culture has a profound influence on the legal system and how it operates in different countries. China adopted a laissez-faire approach to providing a structure by which individuals could economically benefit from their ideas, a situation that stems from their cultural history, which is heavily influenced by Confucius and communism
(Botta and Tsai, 2004). Therefore, it should have been expected that China was not going to implement a hard-nosed patent system with which to rigorously act against infringement in a short space of time.

The Chinese culture itself is pro-copying, rather than against it. The Chinese legal system evolved to protect the interests of the state and society as a whole, as opposed to those of the individual (Bosworth and Yang, 2000:455). The communist regime of Mao Zedong exalted the idea of collectivism and, as a result, the value of publicly owned property (Botta and Tsai, 2004); the granting of private property was frowned upon. Consequently, China traditionally had a weak patent system. The concepts of IPR and Confucianism have always been at odds with each other, because IPR are governmentsanctioned monopolies that protect the IP owner, while Confucianism holds that learning takes place through copying, and that imitation is a form of flattery (Bosworth and Yang, 2000:455).

The tendency to promote the interests of the state above those of the individual resulted in the lack of implementation of an independent system of administering and enforcing the law (Bosworth and Yang, 2000:455). Furthermore, the emphasis on harmony and self-governance eventually resulted in an aversion to conflict. Despite the sheer size of its economy and population, China, in 2000, was still a Third World country, unable to generate sufficiently high levels of information and advanced techniques to meet their desire for development. Singapore's advance illustrated quite clearly the contribution that technology transfer can make in achieving growth. Thus, the internal pressure for change at the dawn of the open-door policy implied a move away from Confucianism, Marxism, Leninism, and the doctrines of Mao Zedong (Bosworth and Yang, 2000:460).

\section{A changing approach}

De Meyer (2001:140) cited three forces that are creating a more favourable background for multinational companies to do new business in China through technology transfer. The first 
is that China requires technology that leads to innovation and improvement that also form part of their development strategy. Secondly, there is a changing attitude in the Chinese government to demand the latest technology, rather than previous-generation technology, and, thirdly, IPR is better respected.

Since the late 1970s, China moved from viewing IP as public property to a country with a host of modern IP legislation. Bosworth and Yang (2000:453) associated this change in approach to an upsurge in IP activity in China since 1985. China realised that IP laws were a prerequisite for trade, FDI, and the associated economic growth.

Despite being contradictory to the culture, an IPR system also ran counter to the People's Republic of China's (PRC's) planned economy. Individual welfare was, and arguably still is (at official levels, at least), subordinate to social welfare and national interest (Bosworth and Yang, 2000:456). From 1949 to 1978 , there were no effective IPR laws in the PRC, while the central government exercised stringent administrative control over inventions and publications. This control is illustrated by the fact that, between 1950 and 1963, only four patent rights and five inventions were granted in the PRC. A 1963 law stipulated that all inventions are national assets, stifling innovation. With the start of the opening of the economy, a Patent Office was established, in 1980. Since 1982, a series of laws and regulations on technology transfer and IPR protection were introduced, continuing into the 1990s. However, a change in a country's institutional attitude towards IP protection is taking longer. Only recently did the balance shift from administrative authority towards the judiciary (Bosworth and Yang, 2000:458). The general order for addressing disputes in China ranges from judicial litigation, as the least preferred, to non-judicial administrative adjudication, to mediation, which is the most popular.

A strong push for reform since 1978, after the era of Mao Zedong, by the Chinese government marked a victory for the advocates of an outward-facing China that actively takes part in the world economy (Botta and Tsai, 2004).
Dealings with other countries after adopting the open door policy provided Chinese people with the opportunity to see the individualised mode of thinking common in Western countries, and to shift towards capitalism. This change provided the foundations for further reform. The Chinese political leadership started to promote economic development and positive social change in its effort to achieve its goal of becoming a world leader. They realised that, in order to achieve this goal, they had to promote technology and science (Botta and Tsai, 2004). International organisations such as WIPO and the WTO played an important facilitating role in enhancing IP protection in China, as well as in other developing countries.

Currently, China is a member of all of the major international IP conventions, including WIPO, the Berne Convention for Protection of Literary and Artistic Works, the Universal Copyright Convention, the Paris Convention for the Protection of Industrial Property, the Patent Cooperation Treaty, TRIPS, and the Madrid Agreement for the International Registration of Trademarks (Greguras, 2007:449).

China's national objectives are also served by the rapid introduction of IP protection systems. China's desire to acquire advanced technologies from developed countries and its newfound desire to protect its own indigenous technology were internal motivations. China realised that the absence of proper IP protection meant that nobody wanted to transfer technology to China. Yang (2003:137) argued that the Chinese government recognised the need to access new information and technology if it wanted to improve its competitiveness, growth, and development.

Since the early 1980s, China's exports have also gained importance, especially exports of technology. Resultantly, IPR protection became crucial in protecting China's indigenously developed technology. One reason was that $70-80 \%$ of the technology exported from the PRC were destined for other developing countries, many of which possessed weak IPR protection themselves (Bosworth and Yang, 2000:461). 
Chinese business leaders are realising that they have to be able to protect their own IP in both China and international markets (Holstein, 2007:15). The Chinese government faces many challenges, as IP reforms, including legislation and enforcement, will be based on the balance between economic and political consideration (Liu, 2005:339). Enforcement of copyrights and patents pose a trade-off between encouraging domestic inventive activity at the expense of higher consumer prices and large transfers of copyright and patent royalties to foreigners (La Croix and Konan, 2002:768). In each case, the decision to enforce IPR depends on the size and growth potential of the local industry.

\section{International view of China's IPR}

China is a huge market that lacks some sophisticated technologies, and, as a result, is a promising and potentially profitable market for expansion for companies with strong IP portfolios (Liu, 2005:340). Even though China joined the WTO and signed the TRIPS agreement, it cannot satisfy the IPR requirements of industrialised countries and their companies, which is the main barrier in international commercial activities involving technology. In fact, there was a recent dispute between the US and China regarding the poor protection and enforcement of IPR in China under TRIPS. As a result, China amended its copyright law, which was found to be noncompliant with TRIPS (Yu, 2011).

Many global executives view the Chinese market as synonymous with disrespect for IP, and, in some cases, also with the theft thereof (Von Krogh and Haefliger, 2007:23). A good example is the piracy of computer applications, with an estimated $96 \%$ of software being used illegally. However, the booming Chinese market means that companies do not contemplate pulling out of China. Traditional IP protection mechanisms, such as patenting, are all but futile, largely because Chinese companies are proficient in reverse engineering. A long-term approach in which innovation within Chinese partner firms is stimulated and in which they see the incentives will result in a gradual change in local attitudes towards IP.

Von Krogh and Haefliger (2007:24) argued that this is already taking place. Chinese companies themselves are nowadays seeking to enforce IP rights. Recently, Chinese companies have been suing Western companies for patent infringements. In 2006, Netac took PNY Technologies to court in the US, claiming that PNY had infringed a Netac US patent of a flash drive.

The main obstacle in IP protection in China is not its laws, which generally meet international standards, but rather weak enforcement (Greguras, 2007:50). Piracy in many industries continues to impact products, brands, and technologies, and enforcement of both statutory and contractual protection is problematic. It takes between four and seven years for a lawsuit to be heard in China, and monetary compensation is small. Bird (2006:333) argued that, although new interpretations of the Chinese criminal law were recently issued by the Supreme Judicial Court of China, it is questionable whether these interpretations will make any difference with regard to infringements.

In 2001, De Meyer (2001:141) reported that several business people started to form a positive view about China's attitude towards IPR. The situation in China is not worse than in other developing countries, and it is important to remember that IPR in developed countries is also not always exemplary. In addition, Chinese operations are often blamed for leaks that occur elsewhere. Furthermore, Western companies are often naïve, and expose technologies that they should have kept secret.

Another problem experienced in China is the lack of proper technology transfer from the West that takes into account the differences in economic context and culture (De Meyer, 2001:142). Technology developed in the developed world was developed in a context vastly different from that experienced in China. As a result, there is a lack of practical understanding by Chinese workers and engineers. Western companies also observed 
that Chinese partners often want to shortcircuit a few steps in the natural development of knowledge. Education and training are the answer to bridging the differences in approach and understanding, but the training must focus on context and on the different ways of thinking, rather than on the technology.

The reason why so many cases end up being settled outside of the courts can be attributed to the fact that China has always been a country under centralised regimes, where the people were ruled by government and not the law (Yang et al., 2008:324). The culture of avoiding confrontation and resolving disputes outside of the courts is prevalent, and increases the demand for administrative support. The non-judicial track, accounting for settlement of approximately two-thirds of patent infringement cases, $95 \%$ of trademark cases, and most copyright cases, is preferred by companies (Bosworth and Yang, 2000:474). However, this track also presents problems, as arbitration commissions and administration bodies lack adequate numbers of staff with appropriate IP training.

\section{Recent examples illustrating a change in approach}

In 2007, the Beijing High People's Court ruled in favour of Pfizer regarding the validity of Pfizer's Chinese patent covering sildenafil citrate, familiarly known as Viagra (Chen, 2008:30). The case went through a number of courts, and the dispute lasted six years. Pfizer received an undisclosed settlement, but the verdict of the highest court did not stop the competitor from producing this product at the time, a clear indication that enforcement is still an issue in China (Holstein, 2007:16).

There are a number of other examples that illustrate the difficulty of protecting IP in China. Huawei copied Cisco's router technology in order to compete against the US-based company in global markets (Holstein, 2007:16). Even though the two companies reached an undisclosed settlement, Huawei products continue to closely resemble Cisco's. In a high-profile case mentioned earlier, General Motors sued Chery Motors for imitating one of its cars. An agreement between the companies was reached in November 2005, but Chery recently introduced the QQ, an almost perfect imitation of a General Motors product.

Unfortunately, details about most cases are sparse, because lawsuits are usually settled privately. One exception is the case of Starbucks and a competitor in Shanghai that used the Chinese name for Starbucks, Xingbake Cafe. The logo also looked the same, even in colour and style. In 2005, the Shanghai No. 2 Intermediate People's Court ruled in favour of Starbucks, followed by an appeal by Xingbake Café, which they lost in 2006 in the Shanghai Supreme Court (Holstein, 2007:16). However, Xingbake Café continued to do business, regardless of the rulings, leading to the Supreme Court threatening to freeze its bank accounts and seize items. Eventually, Xingbake Café agreed to change its name and pay the settlement of a measly $\$ 63000$, in instalments.

Perhaps the most significant phenomenon is that there were more patent infringements and resultant lawsuits in China than there were in the US in 2005 and 2006, despite the low amount of damages that are granted. In 2005, China saw 2947 patent infringement cases being filed, compared to the 2720 filed in the US (Bai et al., 2007:3). Even more significant is the fact that most of these lawsuits were between Chinese parties, with foreign parties only being involved in about five percent of cases (Chen, 2008:32). Chen (2008:32) believes that the enforcement of IP property rights in China will improve as more parties exercise their legal rights in the courts. Bai (2007:6) believes that multinational companies can successfully enforce patents in China, but that it requires skill, experience, and an understanding of the Chinese system.

Von Krogh and Haefliger (2007:23) argued that multinationals doing research and development $(R \& D)$ in China must be pleased that a Chinese firm recently sued an US company for patent theft, because it suggests that Chinese businesses are acknowledging the importance of IPR.

The IP environment in China is now safer, but not without risks. Despite the risks, Novartis is 
opening a pioneering biomedical R\&D facility in China (O'Connell, 2007:26). Novartis is convinced that China is committed to protecting IPR, and that locating their new R\&D centre in China is an expression of trust. Another reason for Novartis taking this bold step is that the Chinese government encourages people to study science, such as chemistry and engineering, a reverse of the declining trend observed in the West. The quality of education and training in China improved over recent years, with people becoming fluent in English, the lingua franca of R\&D and business (O'Connell, 2007:26).

\section{Stumbling blocks in protecting IP}

Bosworth and Yang (2000:472) argued that, despite new legislation, companies involved with technology transfer and licensing activity in the PRC will continue to experience stumbling blocks with regard to IPR. Enforcement will remain a problem, while the differences in the law, compared to most Western countries, and its interpretation remain difficult. Furthermore, there is a general lack of professional training of Chinese judges and legal officials with respect to IP issues (Bosworth and Yang, 2000:473). Corruption and threats to judges are not unheard of, and on top of that, Chinese judges also have no security of tenure. Difficulties in obtaining evidence make a lawyer's job difficult, while foreign lawyers are prohibited from participating directly in court proceedings.

Before 1979, all aspects of the country, including business, were fully governed by the government (Yang and Clarke, 2005:548). The legal system established to meet the requirements of the open door policy has features comparable to those in many other countries, but the speedy establishment of the legal system means that many legal articles are open to interpretation. The situation is exacerbated by the limited examples in case law. A further complicating factor is the translation of Chinese to English with its ambiguities in rules, regulations, and laws. The original laws are in Chinese, resulting in confusion in the English version (Yang and Clarke, 2005:547).
Other countries and multinational companies do not necessarily understand Chinese law with regard to IP. Bai (2008:5) mentioned that IP licensing in and outside of China is subject to a myriad Chinese laws, regulations, and judicial interpretations that are significantly different from US law. Approaching technology agreements with language common in US legal documents is likely to cause licensing problems in China, because Chinese laws, such as Contract Law, Patent Law, Unfair Competition Law, Foreign Trade Law, and Antitrust Law, differ from laws in other countries in important ways (Bai, 2008:1).

One significant difference is that Chinese law mandates that, if a Chinese licensee makes improvements to licensed technology, the ownership of the improvements belongs to the Chinese company (Bai, 2008:2). In Western countries, it is common practice that the licensee grants ownership rights to the licensor (Bai, 2008:4). The subsequent licensing of an improvement to the original non-Chinese licensor is subject to China's export control regulations that classify technologies into three broad categories. The first is Prohibited Technologies that cannot be imported into or exported out of China. The second is Restricted Technologies that must be approved by the governmental authority prior to the import or export and, thirdly, Permitted Technologies that may be imported or exported without prior governmental approval.

If the agreement is to be enforced in China, certain provisions of Chinese law are mandatory (Bai, 2008:2). Some of these mandatory provisions are counterintuitive for Westerners, and often illegal in the West. Western companies are often confused by these inconsistencies and, as a result, are penalised under Chinese law for invalid contracts (Bai, 2008:3).

Holstein (2007:14) stated that companies are realising that they have not done the best possible job in guarding against theft when setting up their Chinese operations. Incredible as it may seem, most companies assumed that the Chinese operating environment is similar to the familiar environments in the West. A 
practical step in ensuring that Chinese staff are loyal to the company is to train them on ethical expectations, something not covered in their educational system.

A problem with enforcement in China is that it is far from a single political entity. Tough laws implemented at the national level are often ignored at the local level (Sperling, 2004), and the vastness of the country makes enforcement an even bigger task.

\section{PATENT APPLICATION TRENDS}

In an effort to show the change in approach to IP by China and the other BRICS countries, this section shows the trends in patent applications in these countries, as well as their involvement in Patent Cooperation Treaty (PCT) filings and patent applications in the US. The PCT is an international treaty between 148 Paris Convention countries, making it possible to ensure priority for inventions simultaneously in each of the member countries by filing a single patent application, instead of filing several separate national or regional patent applications (WIPO, 2013B).

The US is used as a comparison from the developed world. Patent applications are used because it is an indication of trust and whether companies and individuals perceive it as worthwhile to have a patent in the relevant country. All the data used to draw the graphs were obtained from WIPO (2013A).

However, it is important to remember that the motivation to apply for a patent in a specific country depends on a number of things. First of all, the applicant must believe that the legislation there is strong enough to provide protection. Adherence to global rules and being part of global treaties such as TRIPS will also result in an increase in applications. Coupled to this is legislation and the enforcement thereof in preventing others from infringing on a patent. The political and business environment must be conducive to doing business, thus ensuring that a patent can be used in a specific country, otherwise there is no point in filing a patent. The economy of the country must also be strong enough to lure companies to do business in the country, i.e. the prospects for economic gains must be sufficiently substantial to motivate the effort to file a patent.

Below are a number of graphs that show the differences in the trends in patent applications in the BRICS countries. First of all, it is worthwhile to look at what happened in the US with regard to patent applications since 1985 (Figure 2).

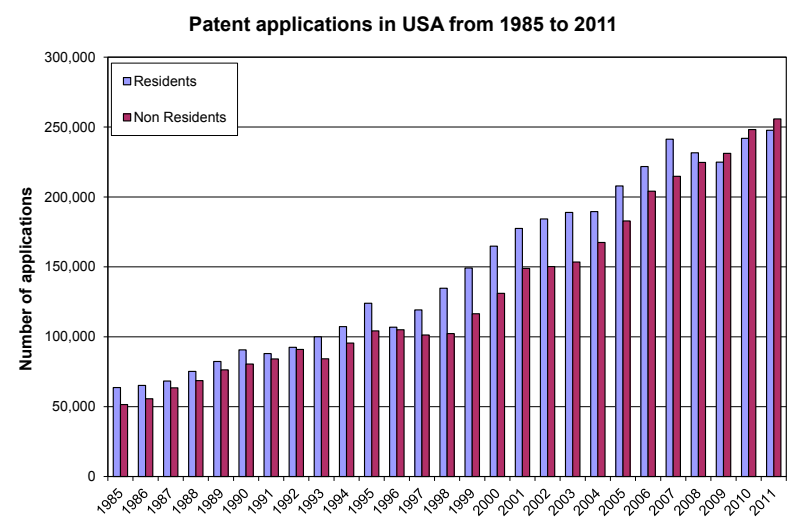

Figure 2: Patent applications in USA from 1985 to 2011

The reason for looking at the trend in the US is that it has a long history of IPR that was not really influenced by international treaties and agreements such as TRIPS, and because it has been the biggest economy globally for quite some time. The steady increase in patent applications clearly shows that there has not been any big event that shaped the patent environment and prompted a different trend in patent applications. Patent applications have been rising steadily, with a small decline during the financial crisis. The five major fields of technology represented in the applications of the last 15 years were computer technology, medical technology, pharmaceuticals, organic fine chemistry, and electrical machinery, apparatus, energy.

On the other hand, patent applications in China have been increasing exponentially since 2000 (see Figure 3). The increase in non-resident patent applications, albeit slowly at first, started in 1992. This upsurge appears to coincide with the PRC's modification of its patent laws in 1990 and 1992 to be compatible with international practice (Bosworth and Yang, 2000:465). China's 
entry into the WTO and TRIPS in 2002 did not change the trend in patent applications. Significantly, patent applications from both nonresidents and residents increased exponentially over the time period. The increase in resident applications is a clear change in approach to IP by Chinese citizens, while the increase in nonresident patent applications indicates that foreign companies either realised the importance of the Chinese economy or started to trust the Chinese commitment to IPR, or both.

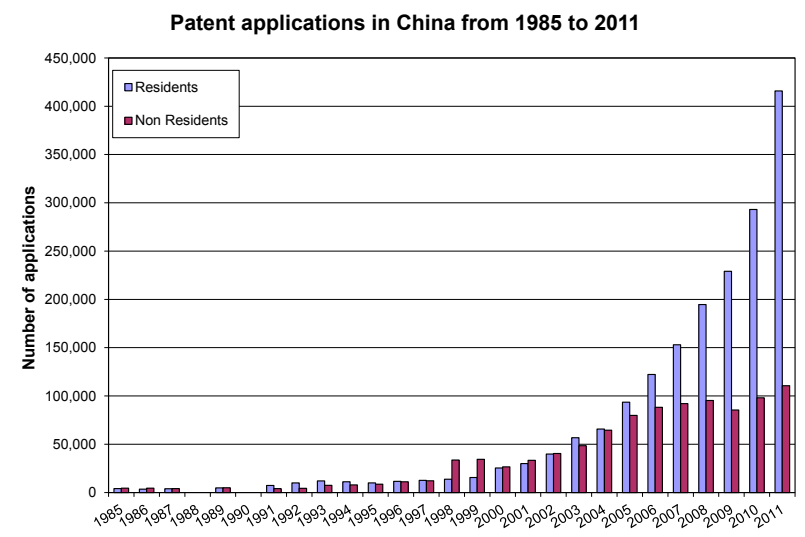

Figure 3: Patent applications in China from 1985 to 2011

During the same period, China's share of the world merchandise export increased from $1.2 \%$ of world trade in 1983 to $8.2 \%$ in 2006 (WTO, 2008). At the same time, merchandise imports increased from $1.1 \%$ to $6.5 \%$ of world trade, a clear indication of China's growing importance in the world economy. The top five fields of technology - digital communication, pharmaceuticals, computer technology, electrical machinery, apparatus, energy, and measurement - differ from those of the US.

The trend in Brazil followed a distinctly different pattern (Figure 4). There was a step change in 1997 for non-residents, followed by a gradual increase since 2006, again mainly from non-residents. The hosting of the Soccer World Cup in 2014 and the Olympics in 2016 may have played a role in this increase. The step change can be attributed to Brazil joining the WTO, and thus TRIPS, in 1995. Contrary to China, Brazil's part of global export merchandise stayed flat at $1.2 \%$ from 1983 to 2006 , while merchandise imports decreased from $0.9 \%$ to $0.8 \%$. This could be attributed to Brazil's role in the world economy. The focus on infrastructure development is also clear in the major technology areas being patented over the last 15 years: civil engineering, transport, other special machines, handling, furniture, and games.

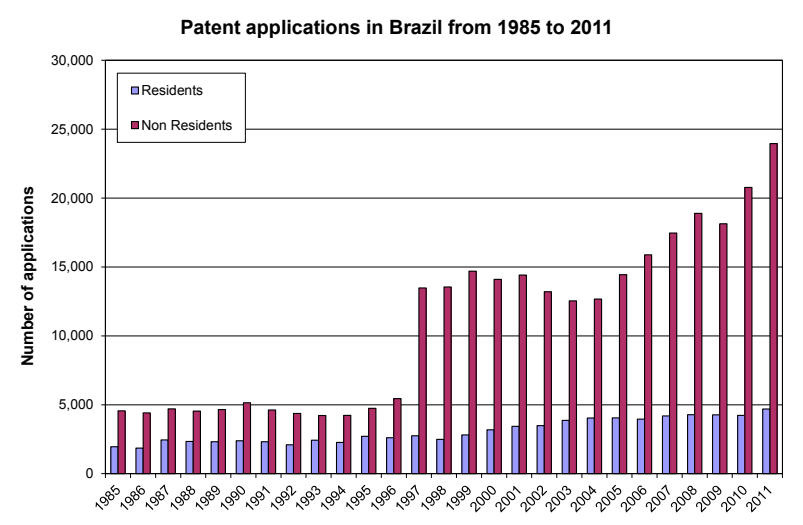

Figure 4: Patent applications in Brazil from 1985 to 2011

The Russian Federation only came into being after the fall of communism, and therefore only data from 1991 is available (Figure 5). The decrease in patent applications from 1992 to 1997 can probably be attributed to the fall-out of the end of the Soviet Union.

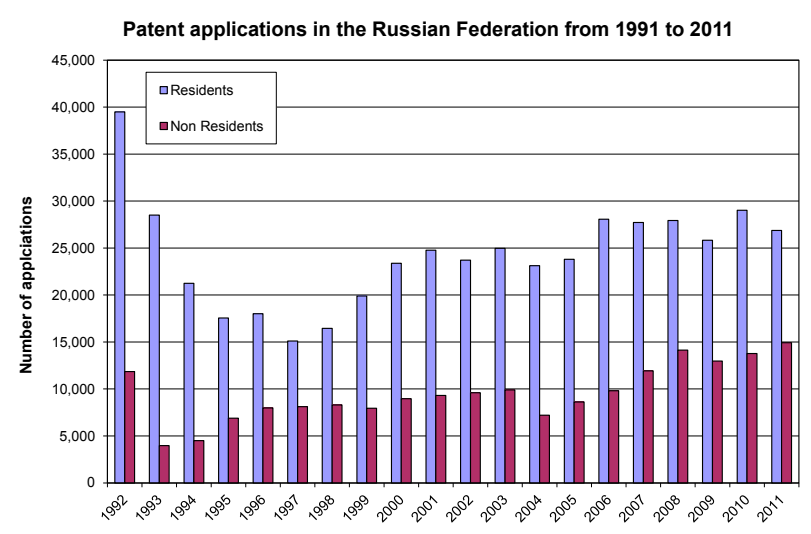

Figure 5: Patent applications in the Russian Federation from 1991 to 2011

What is more striking is that there was no significant increase in non-resident patent applications up to 2009. This is probably due to a lack of trust after recent nationalisations and an aversion due to the financial crises of the late 1990s. There may also be a perception of political risk that convinces inventors not to file patents in the Russian Federation. The Russian Federation 
only joined the WTO in August 2012, and any impact on patent applications will only be seen in years to come. The absence of pharmaceuticals and electronic areas are evident in the top five technology areas for patent applications: food chemistry, medical technology, measurement, civil engineering, and materials and metallurgy.

India's graph shows a very interesting trend (Figure 6). In general, the trend is exponential, although not as profound as that of China. What is interesting is that non-resident applications are the real reason behind the exponential increase since 1999.

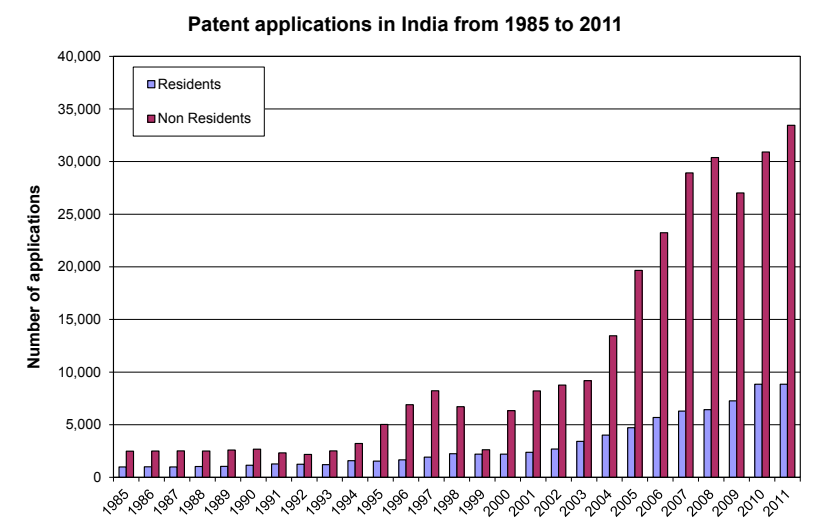

Figure 6: Patent applications in India from 1985 to 2011

It is possible that the reason why resident applications are only increasing linearly is because the government did not do enough to ensure a change in mind-set, as happened in China, with regard to patent filing, but it could also be that the Chinese government did more to stimulate research. During the same period, India's share of both the world merchandise export and import doubled (WTO, 2008). Chemistry-related technology areas are the main focus for patent applications, with pharmaceuticals, organic fine chemistry, biotechnology, computer technology, and basic materials chemistry being the top five. Interestingly, pharmaceuticals and organic fine chemicals combined constitute almost 50 percent of all applications, while representing only 11 percent or less in the other countries mentioned here, and not even making the top ten in Brazil.

In South Africa, the latest addition to the BRICS, a sharp decline in patent applications coincided with the political change of the early 1990s, while the impact of the Asian financial crisis in the latter half of the same decade is most probably the reason for the sharp decline observed in that period (see Figure 7). It is important to note that South Africa has, over time, developed a substantial amount of patent case law, together with a significant number of legal professionals specialising in IP. The patent application fields are also relatively fragmented, with the top eight technology areas all receiving within 4.5 to 7 percent of the total applications. The stagnation in patenting activity originating from South Africa is also evident in Figures 8 and 9. Speculation on the reason would be the subject for another paper.

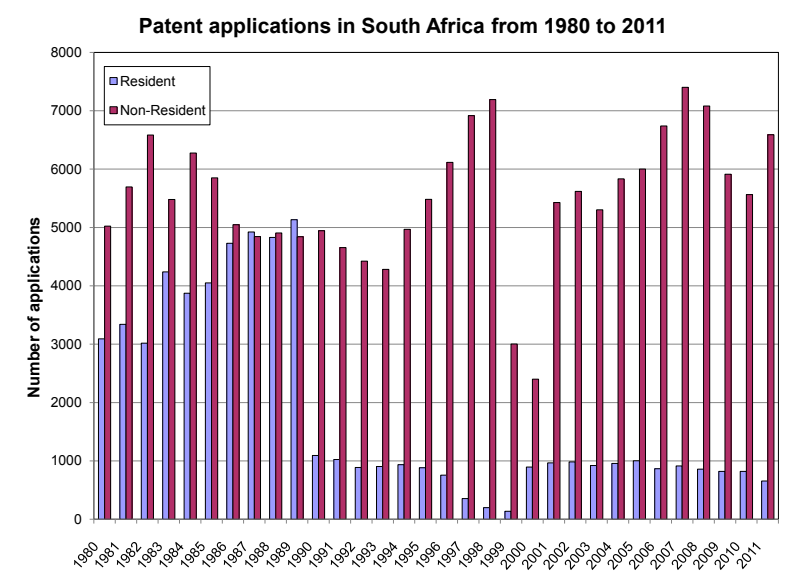

Figure 7: Patent applications in South Africa from 1980 to 2011

The gradual increase in Indian applications is visible in the number of patent applications that originated from India and were filed in the US (see Figure 8). On the other hand, China's total applications in the US increased exponentially. Disappointingly, the applications originating from Brazil and the Russian Federation hardly increased since the start of the decade. A similar picture is seen in PCT filings since 2000 (Figure 9), clearly indicating that Chinese companies and inventors increasingly recognise the PCT as an important channel for the filing of patents. PCT filings in the US originating from India as a percentage of total filings have not increased significantly, while the other BRICS countries have increased this percentage. 


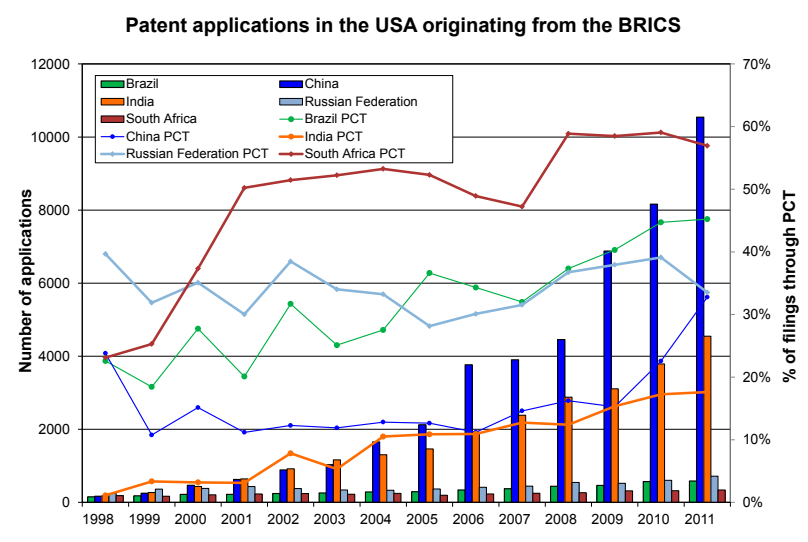

Figure 8: Patent applications in the US originating from the BRICS

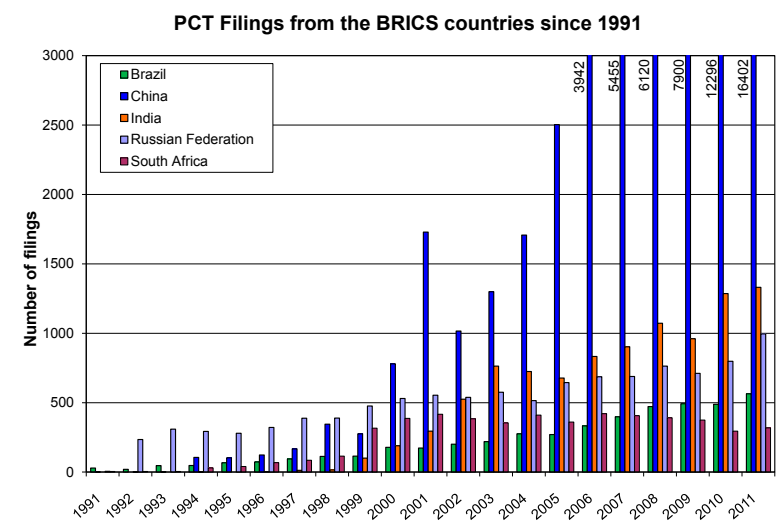

Figure 9: PCT Filings from the BRICS countries since 2000

\section{CONCLUSION}

Globalisation has forever changed the environment in which everyone is competing. International institutions play a significant role in setting the rules for business in the globalised world. Being members of these institutions and signatories of treaties is non-negotiable if countries want to play in the global economy and its various markets.

Global institutions are still dominated by the major developed countries, which are democratic countries with market-orientated economies. Consequently, the rules of the institutions are heavily influenced by Western countries' policies. Developing countries have had to change their policies to subscribe to these rules, in order to enter the lucrative Western markets, and thus the world economy.
There is a convergence of developments in legal regimes around the globe, meaning that specificity of IP protection is breaking down (Basant, 2004:76). IPR and protection are relatively new for many companies in the developing world, but they are beginning to learn how to grapple with these, especially in countries where governments are encouraging the role of IP, as is the case in China (Mathur, 2007:43).

China had to adopt certain market-orientated policies to increase its prospects to become a member of the WTO, changes that can be directly related to the influence of globalisation. The desire of the political leadership in China to transform the country into an economic powerhouse and global leader meant that they had to make changes that run counter to the Chinese culture. The significant increase in patent applications domestically and abroad is an indication that companies bought into the new policies. All these changes are also followed by changes in legal environments, and even though enforcement in developing countries is not yet at the desired levels, it is improving.

However, these changes can take some time to manifest, a fact seen in the lag between policy changes and observing tangible changes in approach to IPR, as observed in China.

Von Krogh and Haefliger (2007:24) postulated that the IP environment in China will improve considerably in the next ten years, but only if both Chinese and foreign companies continue to make a concerted effort in generating respect for IP through understanding of the value of IP, and developing the competence in using IP properly and effectively. There are indications that this is indeed happening, largely brought on by China's desire to become a leader in the world economy and the resultant policy and structural changes it brought about, aligned with provisions of the TRIPS agreement. Furthermore, the Chinese economy is growing at a phenomenal pace, increasing the willingness of companies to enter the Chinese market.

Convergence towards a global ethic and acceptable business ethical decision-making are 
unavoidable in the current interconnected world Although it will take some time, an inclusive and single worldview that builds on already existing global ethics will eventually develop. Exactly how the final convergence of a global ethic will look, and when it will be reached, will only be evident in time.

\section{References}

Adamo, K. R., McCrum, R. B., and Gerber, S. M. 2008. The curse of 'copying.' The fohn Marshall Review of Intellectual Property Law, 296-324.

Adams, S. 2008. Globalisation and income inequality: Implications for intellectual property rights. Journal of Policy Modeling, 30 (5), 725-735.

Bai, B. 2008. Avoiding IP licensing pitfalls in China. The Licensing fournal, 28 (2), 25.

Bai, B., Wang, P., and Chen, T. 2007. How to litigate patents in China. China IP Focus, 3-6.

Basant, R. 2004. Intellectual property and innovation: Changing perspectives in the Indian IT industry. Vikalpa, 29 (4), 69-82.

Bird, R. C. 2006. Defending intellectual property rights in the BRIC economies. American Business Law fournal, 43 (2), 317-363.

Boldrin, M. and Levine, D. K. 2006. Globalisation, intellectual property, and economic prosperity. Spanish Economic Review 8, 23-34.

Bosworth, D. and Yang, D. 2000. Intellectual property law, technology flow and licensing opportunities in the People's Republic of China. International Business Review, 9, 453-477.

Botta, S. and Tsai, C. 2004. Globalisation is a catalyst for change in intellectual property systems: Case studies in India and China. [Online]. Available from: http://net. shams.edu.eg/ecourses/Aeronautics $\% 20$ and\%20Astronautics/under\%20\&grad/ Inventions $\% 20$ and $\% 20$ Patents, $\% 20$ Fall $\% 20$ 2003/pro/1.pdf [Last accessed on 10 May 2008].
Brennan, A. 2006. Globalisation, environmental policy and the ethics of place. Ethics, Place and Environment, 9 (2), 133-148.

Chen, T. 2008. Beijing high court upholds Viagra patent in China. IP Perspectives, 30-32.

$\mathrm{Chu}, \mathrm{A}$. and Peng, S-K. 2011. International intellectual property rights: Effects on growth, welfare and income inequality. Journal of Macroeconomics, 33, 276287.

Collier, J. 2000. Editorial: Globalisation and ethical global business. Business Ethics: A European Review, 9 (2), 71-75.

Credit Control. 2005. Survey reveals major risks involved in trading with emergent markets. 26 (7), 43.

Czub. 2001. Argentina's emerging standard of intellectual property protection: A case study of the underlying conflicts between developing countries, TRIPS standards, and the United States. Case Western Reserve fournal of International Law, 33 (2), 191-231.

Davis, L. 2004. Intellectual property rights, strategy and policy. Economics of Innovation and New Technology, 13 (5), 399-415.

De Meyer, A. 2001. Technology transfer into China: Preparing for a new era. European Management fournal, 19 (2), 140-144.

Dutfield, G. 2005. Turning knowledge into power: Intellectual property and the world trade system. Australian fournal of International Affairs, 59 (4), 533-547.

Dutz, M. A. 2007. Unleashing India's innovation: Toward sustainable and inclusive growth. World Bank, Washington, D.C.

Ganguli, P. 2000. Intellectual property rights. Imperatives for the knowledge industry. World Patent Information, 22, 167-175.

Greguras, F. 2007. Intellectual property strategy and best practices for R\&D services in China. Computer Law \& Security Report, 23, 449-452.

Griffin, K. 2003. Economic globalisation and institutions of global governance. Development and Change, 34 (5), 789-807. 
Grimes, W. 2005. Car Clones and Other Tales of the Mighty Economic Engine Known as China. New York Times, [Online]. Available from: http://www.chinainc-book.com/ review6.html [Last accessed on 2 February 2010].

Grulke, W. 2006. China: Stark realities of a roaring economic dragon. Management Today, July, 39-40.

Holstein, W. J. 2007. Protecting the company jewels in an unprotected country. Research \& Technology Management, 50 (6), 14-16.

Hong, Y. 2001. Ethical issues in the globalisation of the knowledge economy. Business Ethics: A European Review, 10 (2), 87-91.

Küng, H. 1997. A global ethic in an age of globalisation. Business Ethics Quarterly, 7 (3), 17-32.

La Croix, S. J. and Konan, D. E. 2002. Intellectual property rights in China: The changing political economy of Chinese-American interests. World Economy, 25 (6), 759-788.

Lalitha, N. 2004. Diffusion of agricultural biotechnology and intellectual property rights: Emerging issues in India. Ecological Economics, 49, 187-198.

Liu, W. 2005. Intellectual property protection related to technology in China. Technological Forecasting \& Social Change, 72, 339-348.

$\mathrm{Lu}, \mathrm{X} .2001$. Ethical issues in the globalisation of the knowledge economy. Business Ethics: A European Review, 10 (2), 113-119.

Mathur, S. 2007. TRIPS: Issues, impact and the way forward for developing countries including India. American Law \& Economics Association Annual Meetings, Paper 7.

Mondal, D. and Gupta, M. R. 2006. Innovation, imitation and intellectual property rights: A note on Helpman's model. fournal of Economics, 87 (1), 29-53.

O'Connell, A. 2007, Novartis's great leap of trust. Harvard Business Review, 85 (3), March, 26.

Park, W. G. and Lippoldt, D. C. 2008. Technology transfer and the economic implications of the strengthening of intellectual property rights in developing countries. OECD Trade Policy Working Papers, No. 62, OECD Publishing. 25 January.
Security. 2008. Get tough on China, Russia - and Canada, too. March, 33.

Shen, X. 2005. A dilemma for developing countries in intellectual property strategy? Lessons from a case study of software piracy and Microsoft in China. Science and Public Policy, 32 (3), June, 187-198.

SIPO. 2013A. Promotion plan for the implementation of the National Intellectual Property Strategy in 2013. [Online]. Available from: http://english. sipo.gov.cn/about/basicfacts/200904/ t20090415_451001.html [Last accessed on 17 December 2013].

SIPO. 2013B. Promotion plan for the implementation of the National Intellectual Property Strategy in 2013. [Online] Available from: http://english. sipo.gov.cn/news/official/201303/ t20130326_789188.html [Last accessed on 17 December 2013].

Sperling, E. 2004. China IP theft may get worse. Electronic News, 50 (17).

TaylorWessing. 2008. Global Intellectual Property Index Report. London, United Kingdom. May.

TaylorWessing. 2013. Global Intellectual Property Index, The $4^{\text {th }}$ Report. [Online] Available from: http://www.taylorwessing.com/ ipindex/ [Last accessed on 17 December].

Teitel, S. 2005. Globalisation and its disconnects. The fournal of Socio-Economics, 34, 444-470.

The Economist 2007. Imitate or die. In: High-tech hopefuls, A special report on technology in India and China, 10-16 November, 8-10.

The Economist 2008. Inevitable collusion, 23-29 February, 68-70.

The World Bank. 2008b. Doing Business 2009. [Online] Available from: http://www. doingbusiness.org/ [Last accessed on 2 zOctober 2009].

The World Bank. 2011. Economy rankings. [Online] Available from: http://www. doingbusiness.org/rankings [Last accessed on 25 September 2013].

Von Krogh, G. and Haefliger, S. 2007. Nurturing respect for IP in China. Harvard Business Review, 85 (4), 23-24. 
Watson, A. 2011. Does TRIPS increase technology transfer to the developing world? The empirical evidence. Information and Communications Technology Law, 20 (3), 253-278.

Wilson, T. 2007. Fair trade no substitute for intellectual property. Institute of Public Affairs Review, 59 (1), March, 23-24.

WIPO. 2007. WIPO patent report: Statistics on worldwide patent activities. Geneva, Switzerland.

WIPO. 2011. [Online]. Available from: www.wipo. org [Last accessed on 26 February 2011].

WIPO. 2013A. [Online]. Available from: www. wipo.int/ipstats/en/ [Last accessed on 18 December 2013].

WIPO. 2013B. [Online]. Available from: www. wipo.int/pct/en/ [Last accessed on 18 December 2013].

Wang, D. and Clarke, P. 2005. Globalisation and intellectual property in China. Technovation, 25, 545-555.
Yang, D. 2003. The development of intellectual property in China. World Patent Information, 25, 131-142.

Yang, D., Fryxell, G. E., and Sie, A. K. Y. 2008. Anti-piracy effectiveness and managerial confidence: Insights from multinationals in China. fournal of World Business, 43, 321-339.

$\mathrm{Yu}, \mathrm{P}$. 2011. TRIPS enforcement and developing countries. American University International Law Review, 26, 727-782. 